\title{
A HOLISTIC, INTERDISCIPLNARY APPROACH TO THE DESIGN OF A SUSTAINABLE PERSONAL MOBIILTY SYSTEM
}

\author{
Ralph O. Buchal \\ Faculty of Engineering \\ Western University \\ London, Ontario, Canada \\ rbuchal@eng.uwo.ca
}

\begin{abstract}
For the past several years, undergraduate engineering students at Western University have been working on the design of a sustainable personal mobility system (SPMS). The vision of SPMS is to replace privately owned conventional cars with a sustainable mobility system built around shared lightweight electric vehicles, powered by renewable energy. In the 2011-2012 academic year, 13 undergraduate engineering students worked in five teams to further develop SPMS. They examined the economic and business feasibility of SPMS, and developed conceptual designs for the car-sharing system and vehicles. They reviewed the issues around climate change and renewable energy, and added to previous work by exploring the literature from different disciplines to learn more about car-sharing systems, electric vehicles, traffic network modeling and simulation, Monte Carlo simulation, vehicle layout and ergonomics. The students learned to take a holistic, interdisciplinary approach to the complex sociotechnical problem of sustainable personal mobility. While many students were initially uncomfortable with the ambiguity and ambitious scope of the project, they came to appreciate the many sociotechnical factors involved in designing an SPMS. An important learning outcome has been to increase student awareness and understanding of the environmental challenges facing society, as well as possible sociotechnical solutions.
\end{abstract}

Keywords: capstone design; engineering and the environment; interdisciplinary design; sustainable mobility

\section{INTRODUCTION}

Scientific consensus is that the increase in global average temperature must be limited to no more than about 2 degrees Celsius to avoid the worst consequences of climate change. This will require GHG reductions of $80-90 \%$ over the next $10-20$ years [1], [2].

Private vehicles contribute about $20 \%$ of the total global GHG emissions [3]. The International Transport Forum (ITF) forecasts that the number of private vehicles in the world will triple by 2050 , with most of the growth being in developing countries [4]. The ITF forecasts that total GHG emissions from private vehicle use will increase by 2.5 - 3 times, assuming moderate improvements in average fuel economy. This business-asusual scenario is clearly unsustainable if the worst effects of climate change are to be avoided. To reduce GHG by $80 \%$ will require a radical rethinking of personal mobility.

\section{A SUSTAINABLE PERSONAL MOBILITY SYSTEM (SPMS)}

Private cars have emerged as the dominant mode of personal mobility over the past century, particularly in developed countries. Cities and transportation networks have been built to support cars, and not owning a car severely limits personal mobility. Furthermore, cars confer status and a sense of freedom, and car ownership is an aspiration for the majority of the world's population.

However, car ownership is also very expensive. In many urban areas, traffic congestion and lack of parking make driving a car very unpleasant. Car owners reluctantly accept these disadvantages for lack of better alternatives.

There is evidence that consumer behavior is determined by personal rather than social benefits and disadvantages. For example, the clear environmental benefits of current electric cars do not offset their extra cost and limited range in the eyes of most consumers. To be adopted widely, an alternative sustainable personal mobility system (SPMS) must be cheaper, more 
convenient, and more flexible than cars. Most importantly for the environment, it s hould also be sustainable by reducing $\mathrm{GHG}$ from personal transportation by at least $80 \%$.

For the past several years, Western engineering students have been working on the design of an SPMS as an alternative to cars [5], [6], similar to the "mobility on demand" system proposed by MIT researchers [7]. SPMS is an advanced vehicle sharing system, using a fleet of lightweight battery electric vehicles (BEVs) powered by renewable energy. SPMS provides mobility as a service, with dynamic pricing based on use. The vehicles are part of an intelligent, integrated network, rather than standalone objects. Users and vehicles interact through the network to manage reservations, billing, traffic optimization, monitoring, etc.

SPMS is based on the concept of car-sharing. Carsharing systems have been introduced in many places [8], but always on a relatively small scale. To be more widely adopted, car sharing systems must provide easy access to vehicles whenever and wherever they are needed. Systems like car2go have already demonstrated the feasibility of addressing these requirements [9]. Car2go has no fixed stations, and allows one-way trips of any length without reservations. Furthermore, a car sharing system should integrate seamlessly with other modes of transportation.

The environmental and social benefits of car sharing can only be achieved with large scale adoption [10]. The behavior and performance of large scale car sharing systems are difficult to predict in advance, and Ciari et al. [10] recommend the use of an agent-based approach to modeling and simulating such systems. Such simulation studies can help determine fleet size and composition, optimal distribution of stations, dynamic pricing algorithms, and many other design factors. They propose a simulation method using an existing MATSim [11], an existing agent-based traffic simulation tool.

Many studies have shown that BEVs have the lowest well-to-wheel carbon footprint of any available alternative [12], especially when powered by renewable energy sources. The emissions levels are a function of the mix of grid power, and emissions will decline as the grid shifts toward more renewable sources.

SPMS employs a fleet of different vehicle types, so users can select the most appropriate vehicle for each trip. The majority of urban car travel consists of short trips with a single occupant, so SPMS will include a fleet of short-range, single-occupant electric vehicles designed to use as little energy as possible.

Although these vehicles are suitable for most trips, they are not a s ubstitute for private cars since they limit flexibility in terms of capacity and range. Since there is no market for them, vehicles like this do not currently exist. They are not just another electric car.

Based on the SPMS requirements, a short-range, ultralight single-occupant BEV was proposed by Buchal et al. [6]. The vehicle has an estimated mass of $300 \mathrm{~kg}$, powered by a $10-15 \mathrm{~kW}$ motor and a $5 \mathrm{~kW}-\mathrm{h}$ battery pack. The energy use was estimated to be about 30 $\mathrm{W}-\mathrm{h} / \mathrm{km}$ for a standard urban driving cycle. Based on the carbon intensity of the US electric grid in 1999, the carbon intensity for this vehicle is about $20 \mathrm{~g} \mathrm{CO}_{2} / \mathrm{km}$. This is a reduction of over $85 \%$ in $\mathrm{CO}_{2}$ emissions compared to a conventional ICE car, and this reduction will increase as the grid shifts to more renewable energy sources. It appears that reductions of over $90 \%$ are easily achievable.

Sustainable personal mobility is a sociotechnical problem, and requires an interdisciplinary, holistic approach. Relevant engineering disciplines include mechanical, electrical, integrated, mechatronics, environmental, and others. In addition to engineering, SPMS involves business and economics, environmental science, psychology and sociology, urban planning, politics, public policy, and many other disciplines.

\section{RECENT PROGRESS}

In the 2011-12 academic year, the previous work on SPMS was continued by 13 undergraduate engineering students working in five teams. The students included $4^{\text {th }}$ year mechanical engineering students, and $2^{\text {nd }}, 3^{\text {rd }}$ and $4^{\text {th }}-$ year integrated engineering students. All projects were part of design courses in the mechanical and integrated engineering programs.

The student teams worked in parallel on several interdisciplinary aspects of the project: sustainability and business feasibility; design of car-sharing systems; vehicle layout and ergonomics; and vehicle drivetrain and braking. In addition to their specific tasks, every team reviewed the environmental motivation behind SPMS.

\subsection{Sustainability and Business Feasibility Team}

The sustainability and business feasibility team consisted of three students in Western's engineering with business option. Their focus was on the economic as well as technical feasibility of widespread adoption of SPMS. They examined the feasibility of large scale adoption of renewable energy combined with car sharing.

The team modeled and analyzed alternative energy scenarios that replace fossil fuel generators with wind, solar and other renewable sources. In particular, they analyzed the Plan B energy scenario proposed by Lester Brown [1], show in Table 1. The team estimated that the total cost of realizing the Plan B scenario is in the order of 
\$25 Trillion, and that this level of investment is feasible. They estimated that the net reduction in GHG emissions would be about $85 \%$. Further, they calculated that the additional grid capacity required to electrify personal transportation would be about $10 \%$.

Table 1. Percent of total global electricity generation from different sources [1].

\begin{tabular}{|l|l|l|}
\hline & $\mathbf{2 0 0 8}$ & $\begin{array}{l}\mathbf{2 0 2 0} \\
\text { Plan B scenario }\end{array}$ \\
\hline Coal & $40.3 \%$ & $0 \%$ \\
\hline Oil & $5.2 \%$ & $0 \%$ \\
\hline Natural Gas & $19.1 \%$ & $4.8 \%$ \\
\hline Nuclear & $13.7 \%$ & $11.4 \%$ \\
\hline Hydro & $17.5 \%$ & $20.8 \%$ \\
\hline Wind & $\sim 1 \%$ & $37.7 \%$ \\
\hline Solar & $\sim 1 \%$ & $13.5 \%$ \\
\hline Geothermal & $\sim 1 \%$ & $6.3 \%$ \\
\hline Biomass & $\sim 1 \%$ & $5.6 \%$ \\
\hline
\end{tabular}

The team also looked at the feasibility of a large-scale vehicle sharing system like SPMS. They determined that users would save money compared to private car ownership if they travel less than about $13,000 \mathrm{~km} / \mathrm{year}$, and that the SPMS could be operated profitably with 5-10 users per vehicle.

\subsection{Car-sharing System Design Team}

The system design team reviewed the literature on carsharing systems, and found that car-sharing users identify convenience and cost as the two most important factors [13]. This leads to the following desirable attributes of a car-sharing system:

- Minimum door-to-door travel time (including any wait time for a vehicle). In particular, the door-todoor time should be less than for alternative modes, and at least equal to cars.

- Availability of a vehicle with the required range, passenger and cargo capacity for each trip.
- Ease of locating and reserving required vehicle. No reservations should be required, and it should be possible to pick up and drop off a vehicle anywhere.

- Low cost compared to alternatives. In particular, it should cost less than owning a car.

The team reviewed the transportation literature, and identified the importance of traffic simulation models in designing transportation systems. There are two complementary approaches: macro models to simulate large, complex networks using simplified road layouts, and micro models to simulate the movements of individual vehicle and how this relates to performance to the system as a whole. One of the best available tools is the MATSim (Multi-agent Transport Simulation) toolkit [11].

The team investigated vehicle-to-grid (V2G) integration for SPMS. V2G has several requirements, including: an electrical connection to the grid; a communication link for monitoring and control; and intelligent metering for managing charging and electricity usage and billing.

This team investigated the technological infrastructure required to support SPMS. They surveyed the latest research in Intelligent Transportation Systems (ITS), and Vehicle Ad Hoc Networks (VANets). These technologies allow a fleet of vehicles to communicate with each other, and with a ce ntralized management system. These technologies can be used to manage vehicle reservations, dynamic pricing, traffic flow optimization, system performance monitoring, load balancing, and many other things. The result is a seamless, integrated user experience. The required technologies are available, and there are no significant technological barriers to widespread implementation. The team recognized that a larger obstacle is changing the way people think about cars and personal mobility.

\subsection{Layout and Ergonomics Team}

The layout and ergonomics team investigated the overall vehicle layout and configuration of a single-seat BEV suitable for single-occupant urban travel. A topdown design approach was used, starting with the driver. A parametric layout model was created in SolidWorks, shown in Figure 1. 


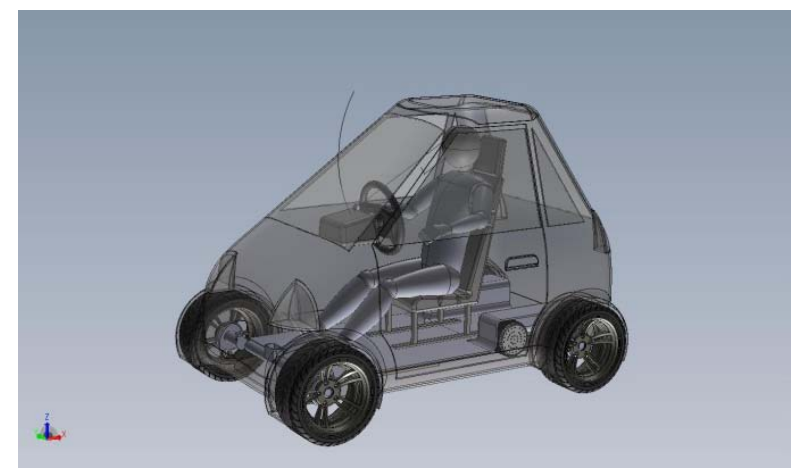

Figure 1. Vehicle conceptual layout.

The team developed conceptual designs for two different vehicles: a functional prototype that could be built by students, and a conceptual design that could be produced in volume. By working on these in parallel, students understood that a student-built prototype has different requirements and constraints than a mass produced vehicle.

For the prototype, the team recommended the use of a steel space-frame chassis with a f iberglass body. The vehicle will have four wheels, with rear-wheel drive. Each rear wheel will be chain-driven, powered by two brushless DC motors. They recommend rack and pinion steering, and double wishbone suspension.

The team designed the driver compartment based on ergonomic considerations. Using anthropometric data, four body types were considered: female (5- and 50percentile) and a male (50- and 95-percentile). The focus was on ergonomics, visibility, control layout, and entry/exit. Particular attention was paid to the ergonomic requirements of elderly drivers.

\subsection{Drivetrain and Braking Team}

The objectives of this team were to further refine the vehicle models previously developed, and to refine the design of the drivetrain and braking systems. Monte Carlo simulation was used to account for uncertainty in the model parameters. The modeling and simulation was done using Goldsim Monte Carlo software [14]. The simulation models were used to establish energy consumption and power requirements for various driving schedules. This data was used for sizing of the motors and battery packs.

A range of possible values was estimated for each of the model parameters listed in Table 2, along with a justification. These parameter values were modeled as triangular probability distributions in Goldsim.
Table 2. Vehicle model parameter values.

\begin{tabular}{|l|l|l|}
\hline Parameter & $\begin{array}{l}\text { Range of } \\
\text { values }\end{array}$ & Justification \\
\hline Mass & $450-550 \mathrm{~kg}$ & $\begin{array}{l}\text { Comparable to } \\
\text { similar electric } \\
\text { vehicles }\end{array}$ \\
\hline $\begin{array}{l}\text { Frontal } \\
\text { Area }\end{array}$ & $1.2-1.8 \mathrm{~m}^{2}$ & $\begin{array}{l}\text { Comparable to } \\
\text { similar electric } \\
\text { vehicles }\end{array}$ \\
\hline $\begin{array}{l}\text { Coefficient } \\
\text { of Drag }\end{array}$ & $0.2-0.3$ & $\begin{array}{l}\text { Comparable to } \\
\text { similar electric } \\
\text { vehicles }\end{array}$ \\
\hline $\begin{array}{l}\text { Coefficient } \\
\text { of Rolling } \\
\text { Resistance }\end{array}$ & $0.01-0.015$ & $\begin{array}{l}\text { Comparable to tires } \\
\text { available on the } \\
\text { market }\end{array}$ \\
\hline Air Density & $1.164-1.397$ & $\begin{array}{l}\text { Temperatures } \\
\text { between -20 to } 30 \\
\text { deg C }\end{array}$ \\
\hline Range & $50-70 \mathrm{~km}$ & $\begin{array}{l}\text { Estimated range for } \\
\text { urban commutes }\end{array}$ \\
\hline
\end{tabular}

The Urban Dynamometer Driving Schedule (UDDS) [15] driving schedule shown in Figure 2 was used to estimate the power requirements and energy consumption. The schedule is a standard benchmark for typical urban trips involving low speeds and stop-and-go driving.

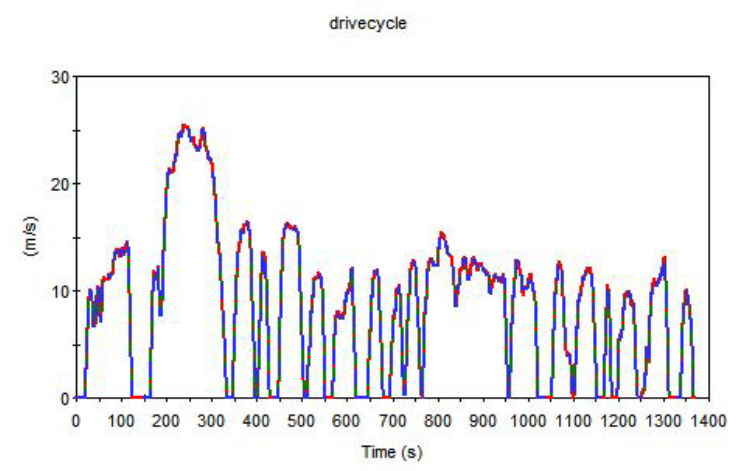

Figure 2. UDDS driving cycle.

The simulation was run for 100 realizations. Each realization calculates outputs based on different input values generated from the defined probability distributions. The energy consumption for the vehicle was found to be $43 \pm 6 \mathrm{~W}-\mathrm{h} / \mathrm{km}$ ( $90 \%$ confidence level). 
These results are a bit higher than the previous estimate of $30 \mathrm{~W}-\mathrm{h} / \mathrm{km}$. However, the team estimated the total vehicle mass to be $450-550 \mathrm{Kg}$, compared to the previous estimate of $300 \mathrm{Kg}$.

The team also determined that regenerative braking could reduce energy consumption by up to $20-30 \%$. For a rear-wheel drive vehicle, alternative braking strategies need to be investigated to maximize regenerative braking.

Figure 3 shows the sensitivity of energy use to variations in the different parameters. For example, energy use varies from 39.5 to $47.5 \mathrm{~W}-\mathrm{h} / \mathrm{km}$ as rolling resistance increases from 0.10 to 0.15 . This sensitivity analysis is a powerful tool for identifying the most significant sources of uncertainty in the model results, and to identify parameters to optimize.

Tornado Sensitivity Chart - Analyzed Result: Total_Energy [kwh/km]

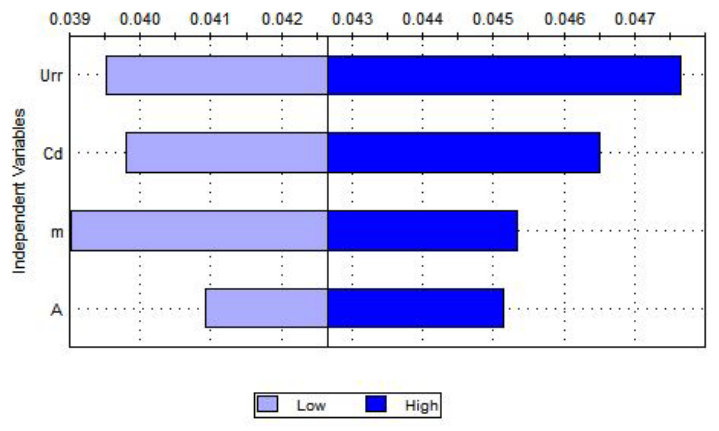

Figure 3. Goldsim sensitivity chart.

Based on vehicle modeling, the drivetrain team estimated the required battery capacity to be $3.5 \mathrm{~kW}-\mathrm{h}$, and the required motor power to be at least $11 \mathrm{~kW}$. This agrees well with the previous estimates of $5 \mathrm{~kW}-\mathrm{h}$ and 10 $15 \mathrm{~kW}$.

\section{LEARNING OUTCOMES AND OBSERVATIONS}

The broad, interdisciplinary nature of SPMS forces students to take a holistic, sociotechnical approach. Students spent considerable time grappling with the issues, and reviewing the relevant literature from different disciplines. At the beginning, their understanding of global warming, renewable energy and transportation alternatives was somewhat narrow and naïve. They were surprised by the impact of cars on global warming, and that small improvements in fuel economy would not be enough to avert climate change. The overall ideas of SPMS were met with skepticism initially, but after weeks of research and discussion, the students came to recognize the importance of the problem, and accepted SPMS as a feasible solution from economic, technical and social viewpoints. While the work built on previous efforts, students spent several weeks researching, debating and internalizing the previous findings. It was not enough to just tell them - it was important for students to discover it for themselves.

Students were uncomfortable with the broad scope, ambiguity and open-ended nature of the project, and had difficulty identifying specific tasks and deliverables. There was a tendency for students to focus on narrow details rather than the big picture. By the end of the project, students became more comfortable with developing simple models and quantitative estimates in the face of uncertainty. They came to appreciate that even though an estimate contains uncertainty, it is not same as a guess. Despite initial skepticism, several teams discovered the value of Monte Carlo simulation when parameter values are not known with certainty.

In the past year, students added to the previous SPMS knowledge base in several related areas, including: car sharing systems, traffic network simulation, intelligent transportation systems, vehicle ad hoc networks (VANets), etc. Students were forced to do more literature review than they were used to, and to recognize and critically assess the authority of their sources.

At the end of the project, all of the students involved demonstrated a much better understanding of the environmental challenges facing society, as well as the sociotechnical issues and possible engineering solutions. This was demonstrated in design reviews, written reports and individual reflections and lessons learned reports.

\section{CONCLUSIONS}

Design of a Sustainable Personal Mobility System (SPMS) to reduce GHG emissions while maintaining or improving personal mobility requires a holistic, interdisciplinary design approach. A project like this has great educational value, and can develop many of the attributes and abilities required by engineers to successfully address important and complex sociotechnical problems.

\section{Acknowledgements}

The author wishes to acknowledge the contributions of the Western engineering undergraduate students involved in this project. They include Reginald Adams, Chris Bacik, Will Bonnycastle, Michael Bunt, David Drysdale, Kelvin Kwok, Adam Lau, Jay Pellerin, Kamil Omozik, Cristina Osorio, Andrew Ravenhurst, Charles Vitanza, and Joey Zhou. 


\section{References}

[1] Brown, L., Plan B 4.0: Mobilizing to Save Civilization. New York; London: W. W. Norton, 2009. Available as of May 17, 2012 from http://www.earthpolicy.org/

[2] Monbiot, G., Heat: How to Stop the Planet Burning. London; New York: Allen Lane, 2006.

[3] Nurul Amin, A.T.M., Reducing Emissions from Private Cars: Incentives for Change, United Nations Environment Programme (UNEP), 2009. Available as of May 17, 2012 from http://www.unep.ch/etb/publications/Green\%20Economy/ Reducing\%20emissions/UNEP\%20Reducing\%20emissio ns $\% 20$ from $\% 20$ private $\% 20$ cars.pdf

[4] Anon, Transport Outlook: Meeting the Needs of 9 Billion People, International Transport Forum, OECD, 2011. Available as of May 17, 2012 from http://www.internationaltransportforum.org/Pub/pdf/11Ou tlook.pdf

[5] Buchal, R. O., "Designing the car of the future", in Proc. Canadian Engineering Education Association (CEEA) Inaugural Conference, Kingston Ontario, June 79, 6 pp., 2010.

[6] Buchal, R. O., Day, A., Robinson, J.C., "Design of a sustainable personal mobility system (SPMS)", in Proc. Canadian Engineering Education Association (CEEA) 2011 Conference, St. Johns Newfoundland, June 6-8, 6 pp., 2011.

[7] Mitchell, M. J., Borroni-Bird, C.E., Burns, L.D., Reinventing the Automobile: Personal Urban Mobility for the 21st Century. MIT Press, 2010.

[8] Millard-Ball, A., Murray, G., Ter Shure, J., Fox, C., Burkhardt, J. Car Sharing: Where and How it Succeeds, Transit Cooperative Research Program (TCRP) Report 108, Transportation Research Board, Washington, D.C., 2005. Available as of May 17, 2012 from http://onlinepubs.trb.org/onlinepubs/tcrp/tcrp_rpt_108.pdf

[9] Firnkorn, J., Muller, M., "What will be the effects of new free-floating car-sharing systems? The case of car2go in Ulm", Ecological Economics, Vol 70, pp. 1519-1528, 2011.
[10] Ciari, F., Balmer, M., and Axhausen, K. W. Estimating the potential of a large scale car-sharing system with an agent-based microsimulation approach, ETH, Eidgenössische Technische Hochschule Zürich, IVT, Institut für Verkehrsplanung und Transportsysteme, 2010. Available as of May 17, 2012 from http://dx.doi.org/10.3929/ethz-a-006080878

[11] MATSim: Multi-Agent Transport Simulation Toolkit, http://www.matsim.org/

[12] Jacobson, M. Z.,"Review of solutions to global warming, air pollution and energy security", Energy \& Environmental Science, 2009, 2, pp 148-173, 2009.

[13] Lane, C., "PhillyCarShare: First-year social and mobility impacts of carsharing in Philadelphia, Pennsylvania", Transportation Research Record Vol. 1927, pp.158-166, 2005.

[14] Goldsim: Monte Carlo Simulation Software for Decision and Risk Analysis, www.goldsim.com

[15] Dynamometer Driver's Aid, US Environmental Protection Agency. Available as of May 17, 2012 from http://www.epa.gov/nvfel/testing/dynamometer.htm 